\title{
Therapeutic efficacy and safety of botulinum toxin type $A$ in trigeminal neuralgia: a systematic review
}

\author{
Yong Hu, Xiaofei Guan, Lin Fan, Mu Li, Yiteng Liao, Zhiyu Nie and Lingjing Jin*
}

\begin{abstract}
Trigeminal neuralgia is a common disorder caused mainly by compression of the trigeminal nerve root by an overlying blood vessel. Pharmacotherapy and surgery are ineffective or unsuitable in many patients. Therefore, other therapeutic modalities have been tried, including injection of botulinum toxin type A (BTX-A). This study aims to systematically review the therapeutic efficacy and safety of BTX-A in trigeminal neuralgia. PubMed, EMBASE, Cochrane Library Clinical Trials and Web of Science from January 1966 to March 2013 were searched with the terms of "botulinum toxin" AND "trigeminal neuralgia", and references of related articles were traced. Data on the efficacy and safety of BTX-A in this disorder were extracted and analyzed by at least 2 reviewers. Data for individual studies were reported, and pooled data were analyzed if appropriate. Five prospective studies and one double-blind, randomized, placebo-controlled study were identified. Response was achieved in approximately $70-100 \%$ of patients, and the mean pain intensity and frequency were reduced by approximately $60-100 \%$ at 4 weeks after treatment in most studies. Major adverse events were not reported. Available studies show BTX-A may be effective in treatment of trigeminal neuralgia. However, well-designed randomized, controlled, double-blinded trial is still lacking. Future BTX-A treatment studies on optimal dose, duration of the therapeutic efficacy, common AEs, and the time and indications for repeat injection would be promising.
\end{abstract}

Keywords: Botulinum toxin, Trigeminal neuralgia, Systematic review, Therapy

\section{Review} Introduction

Trigeminal neuralgia is a unilateral disorder characterized by brief electric shock-like pains, abrupt in onset and termination, limited to the distribution of one or more divisions of the trigeminal nerve [1]. Epidemiological studies reveal that approximately $4-28.9 / 100,000$ individuals worldwide experience TN [2-5]. It is the most widely recognized neuropathic pain of the face and has been shown to be profoundly distressing the patient's well-being [6]. TN frequently occurs in subjects aged 50-70 years and is more common in women [2,7]. Compression of the trigeminal nerve near the dorsal root entry zone [8-12] by an overlaying blood vessel is a major causative or contributing factor [8]. In addition, it can also be caused by tumor, multiple sclerosis $[13,14]$,

\footnotetext{
* Correspondence: lingjingjin@hotmail.com

Department of neurology, Shanghai Tongji Hospital, Tongji University School of Medicine, Xin-Cun Road 389, Shanghai 200065, China
}

infiltration, amyloid [15-18], small infarcts or angiomas in the pons or medulla [19-21]. In a small fraction of patients, the cause of TN cannot be identified [22].

The treatment of TN continues to be a major challenge due to the complexity of TN's causes and the trigeminal nerve. The antiepileptic drugs, such as carbamazepine $[23,24]$ oxcarbazepine $[25,26]$ and phenytoin $[27,28]$, are commonly used in the treatment of $\mathrm{TN}$, but a substantial proportion of patients have poor response to this treatment, predominantly because of their side effects related to the central nervous system [6]. Eventually, many TN patients become refractory to antiepileptic drugs and other drugs [29-32]. The quality of evidence on the efficacy of neurosurgical procedures (such as percutaneous interventions of the Gasserian ganglion, stereotactic radiosurgery or microvascular decompression [33]) is very low. Although these procedures may relieve the pain to different extents, many may result in sensory side effects. 
Botulinum toxin type A (BTX-A), one of the seven antigenically different botulinum neurotoxins derived from Clostridium botulinum, appears to be the most potent subtype [34]. It can cleave the synaptosome-associated protein of $25 \mathrm{kDa}$ (SNAP-25) in the motor nerve terminals $[35,36]$. BTX-A is reported to be effective in the treatment of migraine and myofacial pain syndrome [37-40]. The mechanism of potential analgesic effect of BTX-A is still unclear. In vitro studies have shown that BTX-A can inhibit the release of pro-inflammatory neuropeptides. Animal experiments also reveal the antinociceptive effect of BTX-A in both inflammatory and neuropathic pain models [41-47]. In 2002, Micheli et al reported the successful treatment of a patient with hemifacial spasm associated with $\mathrm{TN}$ with onabotulinumtoxin $\mathrm{A}$, which opens up new possibilities for its use [48]. After that, several other open-label trials have examined the preventive effects of BTX-A on TN [49-51].

The current review is to systematically review the therapeutic efficacy of BTX-A in TN. The secondary goal of this review was to address the safety and tolerability of BTX-A in the treatment of TN.

\section{Methods}

The methodology utilized in this review followed the review process derived from evidence-based systematic reviews and meta-analyses [52-55] of clinic trials and semi-trials.

\section{Literature search}

A comprehensive search was conducted from 1966 to 2012 using databases including PubMed, EMBASE (OVID), Cochrane Library Clinical Trials and Web of Science. The PubMed, search was conducted by using combinations of Medical Subject Heading (MeSH) search terms and keywords according to the following algorithm: (((“Trigeminal Neuralgia”[Mesh]) OR ((trigeminal [All Fields]) AND neuralgia [All Fields]))) AND ((("Botulinum Toxins, Type A"[Mesh] OR "Botulinum Toxins"[Mesh])) OR botuli* [All Fields]). Other databases were queried by using identical terms for keyword searching. The crossreferencing of bibliographies from notable primary and review articles, and abstracts from scientific meetings and peer-reviewed non-indexed journals were also searched. Only English articles were collected.

At least 2 authors independently, in an unblinded standardized manner, performed searching. Any disagreements were resolved by a third author.

\section{Criteria for inclusion of studies for review}

All studies were reviewed by at least 2 reviewers for inclusion. Any disagreements were resolved by a third author. If there was a conflict of interest with the reviewed manuscripts with authorship, the involved authors did not review the manuscripts.
Types of studies Randomized controlled trials, semitrials (case-control studies, open-label studies and case series studies) were selected for evaluation the efficacy and/or safety of BTX in the treatment of TN. When the selected articles reported the same trial, only the latest study with the largest sample size or longest follow-up period was included.

Articles having no original data (such as letters, editorials, commentaries and reviews) and those without adequate information regarding the outcome were excluded. Nonhuman studies were also excluded.

Types of participants Patients with TN of all ages, sex, and degrees of severity were included. TN was diagnosed according to the criteria developed by the International Headache Society (IHS) or other criteria that conformed in general to the IHS diagnostic criteria [1].

Types of interventions Included studies had to use either a single dose of BTX-A to treat $\mathrm{TN}$, or investigate different dosing strategies. There was no restriction on source of BTX-A, dose of administration, injection sites or number of injections.

Types of outcome measures The primary outcome measure for this review was proportion of responders, defined as patients with at least $50 \%$ reduction in frequency and/or intensity of pain. For the secondary outcomes of interests, we focused on the mean scores of pain, mean attacks per day and treatment-related AEs.

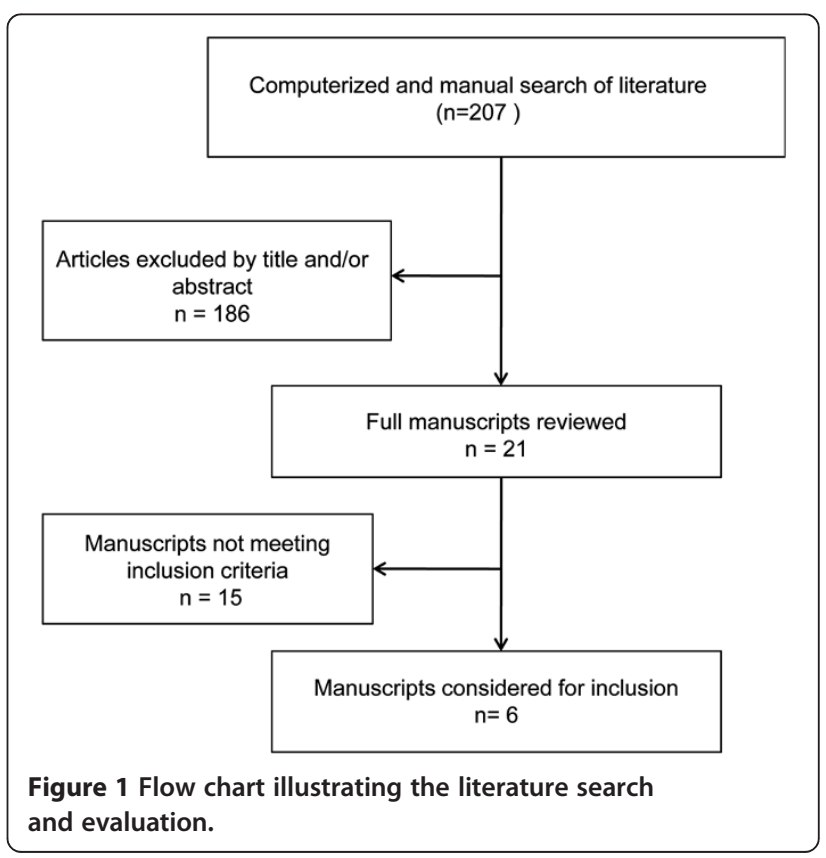


Table 1 Characteristics of studies and patients for systematic review of BTX-A in the treatment of TN

\begin{tabular}{|c|c|c|c|c|c|c|c|c|c|}
\hline Author & No. of patients & Study design & $\begin{array}{l}\text { Level of } \\
\text { evidence }\end{array}$ & $\begin{array}{l}\text { Mean age, } \\
\text { year }\end{array}$ & $\begin{array}{l}\text { Mean duration } \\
\text { before treatment, } \\
\text { year }\end{array}$ & $\begin{array}{l}\text { Frequency of } \\
\text { attacks per day } \\
\text { before treatment }\end{array}$ & $\begin{array}{l}\text { Pain severity before } \\
\text { treatment, VAS }\end{array}$ & $\begin{array}{l}\text { Mean follow- } \\
\text { up, wk }\end{array}$ & $\begin{array}{l}\text { Mean duration } \\
\text { of effect, wk }\end{array}$ \\
\hline Wu et al. [56] & 42 & $\begin{array}{l}\text { Randomised, double-blind, } \\
\text { placebo-controlled }\end{array}$ & $1 \mathrm{~b}$ & 58.6 & 5.9 & 21.2 & 7.0 & 12 & At least 12 \\
\hline Bohluli et al. [57] & 15 & Open-label & 4 & 48.9 & 4.1 & 33.0 & 8.0 & 24 & At least 24 \\
\hline Zúñiga et al. [58] & 12 & Open-label & 4 & 58.5 & 6.2 & $23.4^{\mathrm{a}}$ & $8.8^{\mathrm{a}}$ & 8 & At least 8 \\
\hline Türk et al. [59] & 8 & Open-label & 4 & 57.1 & 1.6 & unclear & unclear & 24 & At least 24 \\
\hline Piovesan et al. [51] & 13 & Open-label & 4 & 61.8 & 8.8 & unclear & 9.9 & 8 & At least 8 \\
\hline Borodic et al. [60] & 11 & Open-label & 4 & $54.2^{b}$ & 10.0 & unclear & unclear & $30.6^{\mathrm{b}}$ & $5-12^{\mathrm{b}}$ \\
\hline
\end{tabular}

a the data of the 10 responded patients.

${ }^{b}$ the data of all the 44 patients of chronic facial pain. 


\section{Data extraction and management}

A standardized form was used to extract the relevant data on the patients' and studies' characteristics, injection protocol, clinical variables, and adverse events by 2 reviewers. Disagreements were resolved by discussion among 3 reviewers.

\section{Data interpretation}

The extracted data were reviewed, interpreted, and discussed to compile into level data according to "Oxford Center for Evidence-based Medicine" criteria (http://www. cebm.net/index.aspx? $0=1025$; updated March 2009) for use in clinical practice. The outcome is integrated in the Results and Discussion sections.

\section{Results}

\section{Literature search}

Figure 1 gives a flow diagram illustrating the results of the literature search for BTX-A therapy in TN. After a comprehensive search, the references of several review articles were checked, the available studies were evaluated, and then 6 trials [51,56-60] were identified. Two studies of Gazerani et al concerning BTX-A in the treatment of capsaicin-evoked TN were not included in this review $[61,62]$.

\section{Study characteristics}

Table 1 illustrates the characteristics of studies on the treatment of TN with BTX-A in this review. The number of patients ranged from 8 to 42; and a total of 101 patients were included in 6 selected studies. The majority of studies were open-label studies, except for Wu's study [56], enrolled 42 patients, in double-blind, randomized and placebo-controlled. Follow-up period ranged from 8 wk to $24 \mathrm{wk}$, except for a study evaluating the impact of repeated injections which lasted 16-80 wk [60].

\section{Injection protocol}

In most of the studies, the amount of BTX-A injected subcutaneously was 20-50 $\mathrm{U}$ in the trigger zones (Table 2). In Wu's study [56], $75 \mathrm{U}$ of BTX-A (Lanzhou Biological
Products Institute) was used in each patient. In addition, 6-9 $\mathrm{U}$ and $100 \mathrm{U}$ were used in two independent studies.

\section{Efficacy}

Primary outcome The proportion of responders, defined as patients with at least $50 \%$ reduction in frequency and/or intensity of pain, was all above $60 \%$ and the mean proportion was $80 \%$ (Figure 2). In Bohluli's study [57], patients with complete eradication of the pain were also reported: the pain was completely eradicated in 7 patients and there was no need for further medication.

Secondary outcomes In studies reporting the effect of BTX-A on the pain intensity, the mean scores measured by VAS were between 7 and 10 at baseline (Table 3). A controlled study demonstrated that the therapeutic efficacy of BTX-A was significantly superior to that of placebo in pain intensity [56]. Open-label trials confirmed this trend [51,57-60]. After BTX-A injection, the reduction in the mean pain intensity from baseline was $41-81 \%$ at $1 \mathrm{wk}, 66-98 \%$ at $4 \mathrm{wk}$, about $80 \%$ at $8 \mathrm{wk}$ and $12 \mathrm{wk}$.

A controlled study and open-label trials also demonstrated that the therapeutic efficacy of BTX-A was significantly superior to that of placebo in reducing daily pain frequency (Table 4). The mean daily attacks were 21-33 at baseline, but 3.6-8.4 at $1 \mathrm{wk}, 4.1-4.7$ at $4 \mathrm{wk}$ and 1.8-2.3 at 8-12 wk after BTX-A injection. In Piovesan's study [51], the average pain area also significantly reduced.

BTX-A was well tolerated in all 6 studies. Although the local or systemic adverse events (AEs) were not very well reported in all studies, most frequent AEs were transient facial asymmetry (Table 5). Facial asymmetry was not severe and resolved within 2 weeks in most studies, except for one patient developing severe side effects which required physiotherapy and took 3 months to resolve in Bohluli's trial [57]. Other reported AEs of BTX-A injection included transient edema (2.2\%), eyelid ptosis (1.1\%), dysesthesia (1.1\%) and difficulty in chewing

Table 2 Injection protocol of BTX-A

\begin{tabular}{lllll}
\hline Author & Source of BTX-A & $\begin{array}{l}\text { Amount of } \\
\text { BTX-A (U) }\end{array}$ & Injection sites & No. of injections \\
\hline Wu et al. [56] & Lanzhou Biological Products Institute, China & 75 & Intradermal and/or submucosal trigger zones & 15 \\
Bohluli et al. [57] & Unclear & 50 & Trigger zones & Unclear \\
Zúñiga et al. [58] & Botox & $20-50$ & Subdermal trigger zones & Unclear \\
Türk et al. [59] & Botox & 100 & Region of the zygomatic arch & 2 \\
Piovesan et al. [51] & Unclear & $6-9$ & Subdermal trigger zones & Varied for each patient \\
Borodic et al. [60] & Botox & $30-50$ & Subdermal trigger zones & Unclear \\
\hline
\end{tabular}




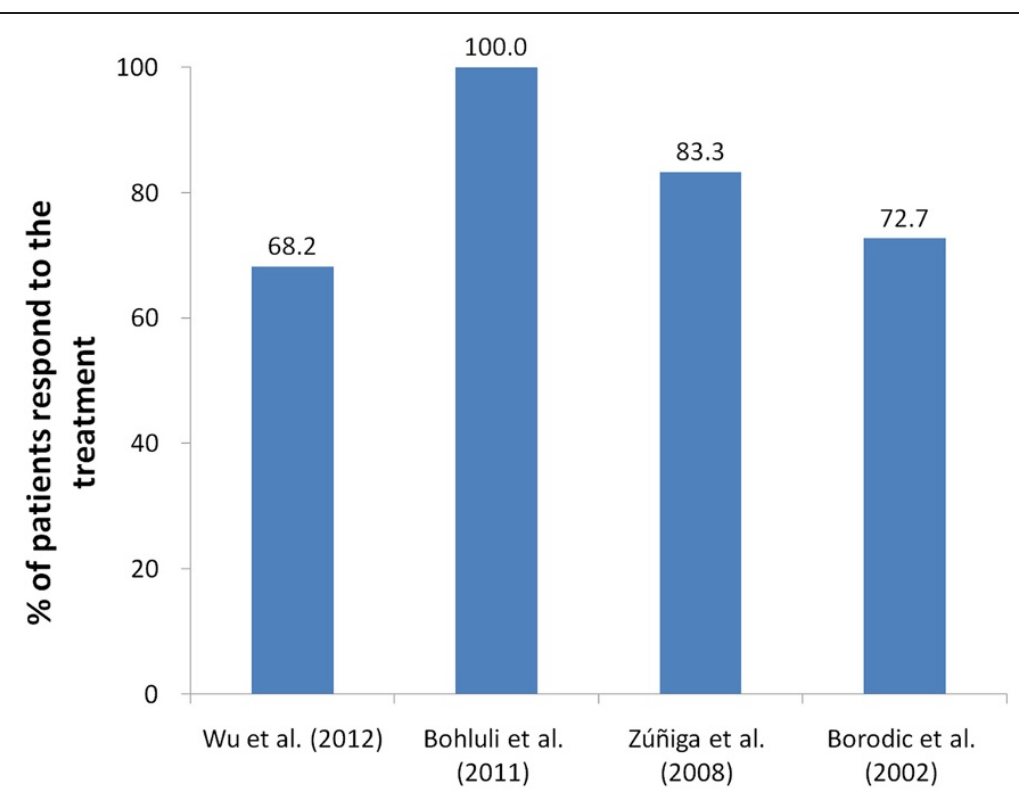

Figure 2 Percent of patients responding to BTX-A treatment.

Table 3 Mean scores of pain measured by VAS

\begin{tabular}{|c|c|c|c|c|c|}
\hline Author & No. of patients & Mean baseline (SD) & Mean end point (SD) & Mean change vs. baseline & Mean \% change vs. baseline \\
\hline \multicolumn{6}{|c|}{ Wu et al. [56] placebo } \\
\hline week 1 & 20 & $6.9(2.3)$ & 4.5 & 2.4 & 35 \\
\hline week 4 & 20 & $6.9(2.3)$ & 4.7 & 2.2 & 32 \\
\hline week 8 & 20 & $6.9(2.3)$ & 5.1 & 2.2 & 26 \\
\hline week 12 & 20 & $6.9(2.3)$ & 5.3 & 1.6 & 23 \\
\hline \multicolumn{6}{|c|}{ Wu et al. [56] BTX-A } \\
\hline week 1 & 22 & $7.1(2.0)$ & 4.2 & 2.9 & 41 \\
\hline week 4 & 22 & $7.1(2.0)$ & 2.4 & 4.7 & $66^{\mathrm{a}}$ \\
\hline week 8 & 22 & $7.1(2.0)$ & 1.4 & 5.7 & $80^{\mathrm{a}}$ \\
\hline week 12 & 22 & $7.1(2.0)$ & 1.4 & 5.7 & $80^{a}$ \\
\hline \multicolumn{6}{|c|}{ Bohluli et al. [57] } \\
\hline week 1 & 15 & $8(1.9)$ & $1.5(1.7)$ & 6.5 & $81^{b}$ \\
\hline month 1 & 15 & $8(1.9)$ & $1.2(1.4)$ & 6.8 & $85^{\mathrm{b}}$ \\
\hline \multicolumn{6}{|c|}{ Türk et al. [59] } \\
\hline week 1 & 8 & Unclear & Unclear & Unclear & Unclear $^{\mathrm{b}}$ \\
\hline month 2 & 8 & Unclear & Unclear & Unclear & Unclear $^{\mathrm{b}}$ \\
\hline month 6 & 8 & Unclear & Unclear & Unclear & Unclear $^{\mathrm{b}}$ \\
\hline \multicolumn{6}{|c|}{ Piovesan et al. [51] ${ }^{c}$} \\
\hline day 10 & 13 & $9.9(0.3)$ & $5.0(3.9)$ & 4.9 & $49^{\mathrm{b}}$ \\
\hline day 20 & 13 & $9.9(0.3)$ & $0.5(2.0)$ & 9.4 & $95^{\mathrm{b}}$ \\
\hline day 30 & 13 & $9.9(0.3)$ & $0.2(1.0)$ & 9.7 & $98^{\mathrm{b}}$ \\
\hline day 60 & 13 & $9.9(0.3)$ & $2.2(2.9)$ & 7.7 & $78^{\mathrm{b}}$ \\
\hline
\end{tabular}

$\mathrm{a} p<0.05$ vs placebo.

b $\mathrm{p}<0.05$ vs baseline.

c mean of three different trigeminal branches. 
Table 4 Mean attacks per day

\begin{tabular}{|c|c|c|c|c|c|}
\hline Author & No. of patients & Mean at baseline (SD) & Mean at the end (SD) & Mean change vs. baseline & Mean $\%$ change vs. baseline \\
\hline \multicolumn{6}{|c|}{ Wu et al. [56] placebo } \\
\hline week 1 & 20 & $20.5(10.4)$ & 18.5 & 2 & 10 \\
\hline week 4 & 20 & $20.5(10.4)$ & 18.8 & 1.7 & 8 \\
\hline week 8 & 20 & $20.5(10.4)$ & 17.7 & 2.8 & 14 \\
\hline week 12 & 20 & $20.5(10.4)$ & 18.2 & 2.3 & 11 \\
\hline \multicolumn{6}{|c|}{ Wu et al. [56] BTX-A } \\
\hline week 1 & 22 & $21.7(22.7)$ & 8.4 & 13.3 & $61^{a}$ \\
\hline week 4 & 22 & $21.7(22.7)$ & 4.7 & 17 & $78^{\mathrm{a}}$ \\
\hline week 8 & 22 & $21.7(22.7)$ & 2.3 & 19.4 & $89^{a}$ \\
\hline week 12 & 22 & $21.7(22.7)$ & 1.8 & 19.9 & $92^{a}$ \\
\hline \multicolumn{6}{|c|}{ Bohluli et al. [57] } \\
\hline week 1 & 15 & $33.0(18.9)$ & $3.6(5.4)$ & 29.4 & $89^{b}$ \\
\hline month 1 & 15 & $33.0(18.9)$ & $4.1(5.8)$ & 28.9 & $88^{\mathrm{b}}$ \\
\hline \multicolumn{6}{|c|}{ Türk et al. [59] } \\
\hline week 1 & 8 & Unclear & Unclear & Unclear & Unclear \\
\hline month 2 & 8 & Unclear & Unclear & Unclear & Unclear $^{\mathrm{b}}$ \\
\hline month 6 & 8 & Unclear & Unclear & Unclear & Unclear $^{\mathrm{b}}$ \\
\hline
\end{tabular}

${ }^{\mathrm{a}} \mathrm{p}<0.05$ vs placebo.

${ }^{b} \mathrm{p}<0.05$ vs baseline.

(1.1\%). Dysphagia and systemic side effects were not reported in all the 5 trials [51,56-60].

\section{Analysis of evidence}

The evidence for BTX-A in the treatment of TN was quantified as Level $1 \mathrm{~b}$ on the basis of one properly randomized controlled trial and multiple open-label studies.

\section{Discussion}

From this systematic review, we can conclude that subcutaneous or mucosal injection of BTX-A is effective for adult TN patients.

Response was achieved in approximately $70-100 \%$ of patients. In most studies, the mean pain intensity and frequency were reduced by approximately $60-100 \%$ at 4 wk after injection. In Bohluli's study [57], $47 \%$ of patients didn't need further treatment;; nonsteroidal antiinflammatory drugs were enough to alleviate pain in $33 \%$ of patients, and $20 \%$ of patients again responded to anticonvulsive drugs after BTX-A injection. In Piovesan's study [51], the pain area was reduced after injection.

Table 5 Treatment-related AEs in the placebo-controlled study of Wu et al [56]

\begin{tabular}{lll}
\hline Adverse events & $\begin{array}{l}\text { Placebo } \\
(\mathbf{n = 2 0 )}\end{array}$ & $\begin{array}{l}\text { BTX-A } \\
(\mathbf{n}=\mathbf{2 2})\end{array}$ \\
\hline Transient facial asymmetry & 0 & $5(23 \%)$ \\
Transient edema & $1(5 \%)$ & $2(9 \%)$ \\
\hline
\end{tabular}

However, in the majority of studies, changes in medications and pain area throughout the study were not clearly described. A better understanding of this field requires more studies In the future.

BTX-A has a faster onset of action with its significant effect reaching within $1-2$ wk and maximum effect within 4-6 wk. Two studies suggest that the effect of a single BTX-A injection could last for 6 mo or approximately 24 wk [57,59], whereas a few studies show the efficacy reduced at 4-8 wk after treatment. The duration that the therapeutic effect continues should be studied in future well designed trials.

Before injection, physicians should adequately inform TN patients about the potential risk of BTX-A-related AEs. Although BTX-A was well tolerated in TN patients, transient facial asymmetry, transient edema, eyelid ptosis, dysesthesia and difficulty in chewing were still reported in 6 studies. To adequately assess the incidence of specific AEs and prevent the underestimate, future studies should adequately document and report the local and systemic AEs.

An important issue is, based on the currently available evidence and physician experience, how BTX-A can be best applied in clinical practice?

The first question is the dosage of BTX-A. The most commonly used dose of BTX-A is 20-75 U. However, Piovesan et al [51] found that 6-9 U of BTX-A induced significant decreases in the pain area and intensity, suggesting that lower doses are also feasible. Türk et al 
[59] also reported the effectiveness after treatment with $100 \mathrm{U}$ of BTX-A. Because no study was designed to compare the therapeutic efficacy of BTX-A at different doses, the optimal dose cannot be concluded. Also, no study was undertaken to compare of the efficacy or tolerance of BTX-A from different manufacturers.

Another variable is the number of injection sites. In Wu's study [56], injection was done at 15 sites. However, injection was done at only 2 sites in Türk's study [59]. It is still unclear if the same efficacy with a less painful and faster injection can be achieved by reducing the number of injections with the same dose of BTX-A.

The optimal indications for re-injection are also important, but they weren't clarified in these studies. In our opinion, re-injection should be performed only when the worsening of symptoms is present. Patients should not receive repeated injections once the symptomatic improvement occurs after two injections, or severe AEs are present.

\section{Conclusions}

We speculate that BTX-A treatment may provide a clinically significant benefit to TN adults. The effect is rapidly achieved, usually within 1-2 wk. Of importance, BTX-A treatment seems to be well tolerated with minimal injections and to result in limited systemic adverse events. Therefore, it represents a promising treatment of $\mathrm{TN}$ with favorable risk-to-benefit ratio. However, welldesigned randomized, controlled, double-blinded trial is still lacking. Future adequately powered studies are needed to investigate the optimal dose of BTX-A treatment, the duration of therapeutic efficacy, common AEs, and the time and indications for repeat injection.

\section{Competing interest}

The authors declare that they have no competing interest.

\section{Authors' contributions}

$L$ and $Y H$ designed this study. $Y H, Y L$ and $X G$ carried out the searches, identified studies for inclusion and extracted relevant data. ML, ZN and LF were involved in analysis. $\mathrm{L}$ acted as arbitrator. All authors read and approved the final version.

\section{Acknowledgements}

The work was supported by National Natural Science Foundation (No: 81000481) and "Fundamental Research Funds for Central Universities" (No: 1508219048). We thank Dr. Qianglin Duan for critical review of this manuscript.

Received: 8 July 2013 Accepted: 18 August 2013

Published: 21 August 2013

\section{References}

1. Headache Classification Subcommittee of the International Headache S (2004) The international classification of headache disorders: 2nd edition. Cephalalgia 24(Suppl 1):9-160

2. Katusic S, Beard CM, Bergstralh E et al (1990) Incidence and clinical features of trigeminal neuralgia, Rochester, Minnesota, 1945-1984. Ann Neurol 27:89-95

3. Hall GC, Carroll D, Parry D et al (2006) Epidemiology and treatment of neuropathic pain: the UK primary care perspective. Pain 122:156-162
4. Dieleman JP, Kerklaan J, Huygen FJ et al (2008) Incidence rates and treatment of neuropathic pain conditions in the general population. Pain 137:681-688

5. Koopman JS, Dieleman JP, Huygen FJ et al (2009) Incidence of facial pain in the general population. Pain 147:122-127

6. Zakrzewska JM (2010) Medical management of trigeminal neuropathic pains. Expert Opin Pharmacother 11:1239-1254

7. Yoshimasu F, Kurland LT, Elveback LR (1972) Tic douloureux in Rochester, Minnesota, 1945-1969. Neurology 22:952-956

8. Devor M, Amir R, Rappaport ZH (2002) Pathophysiology of trigeminal neuralgia: the ignition hypothesis. Clin J Pain 18:4-13

9. Cheshire WP (2007) Trigeminal neuralgia: for one nerve a multitude of treatments. Expert Rev Neurother 7:1565-1579

10. Tomasello F, Alafaci C, Angileri FF et al (2008) Clinical presentation of trigeminal neuralgia and the rationale of microvascular decompression. Neurol Sci 29(Suppl 1):S191-S195

11. Gnanalingham K, Joshi SM, Lopez B et al (2005) Trigeminal neuralgia secondary to Chiari's malformation-treatment with ventriculoperitoneal shunt. Surg Neurol 63:586-588, discussion 588-589

12. Jo KW, Kong DS, Hong KS et al (2013) Long-term prognostic factors for microvascular decompression for trigeminal neuralgia. J Clin Neurosci 20:440-445

13. De Santi L, Annunziata P (2012) Symptomatic cranial neuralgias in multiple sclerosis: clinical features and treatment. Clin Neurol Neurosurg 114:101-107

14. Nurmikko TJ, Gupta S, Maclver K (2010) Multiple sclerosis-related central pain disorders. Curr Pain Headache Rep 14:189-195

15. Benoliel R, Epstein J, Eliav E et al (2007) Orofacial pain in cancer: part Imechanisms. J Dent Res 86:491-505

16. Viviano M, Donati D, Lorenzini G (2012) Metastatic carcinoma presenting as neuralgia involving the trigeminal nerve. J Can Dent Assoc 77:c32

17. Shulev Y, Trashin A, Gordienko K (2011) Secondary trigeminal neuralgia in cerebellopontine angle tumors. Skull Base 21:287-294

18. Bornemann A, Bohl J, Hey O et al (1993) Amyloidoma of the gasserian ganglion as a cause of symptomatic neuralgia of the trigeminal nerve: report of three cases. J Neurol 241:10-14

19. Cheng TM, Cascino TL, Onofrio BM (1993) Comprehensive study of diagnosis and treatment of trigeminal neuralgia secondary to tumors. Neurology 43:2298-2302

20. Singh D, Jagetia A, Sinha S (2006) Brain stem infarction: a complication of microvascular decompression for trigeminal neuralgia. Neurol India 54:325-326

21. Deshmukh VR, Hott JS, Tabrizi P et al (2005) Cavernous malformation of the trigeminal nerve manifesting with trigeminal neuralgia: case report. Neurosurgery 56:E623, discussion E623

22. Nurmikko TJ, Eldridge PR (2001) Trigeminal neuralgia-pathophysiology, diagnosis and current treatment. Br J Anaesth 87:117-132

23. Wiffen PJ, Derry S, Moore RA et al (2011) Carbamazepine for acute and chronic pain in adults. Cochrane Database Syst Rev. doi:10.1002/14651858.CD005451

24. Wang QP, Bai M (2011) Topiramate versus carbamazepine for the treatment of classical trigeminal neuralgia: a meta-analysis. CNS Drugs 25:847-857

25. Nasreddine W, Beydoun A (2007) Oxcarbazepine in neuropathic pain. Expert Opin Investig Drugs 16:1615-1625

26. Gomez-Arguelles JM, Dorado R, Sepulveda JM et al (2008) Oxcarbazepine monotherapy in carbamazepine-unresponsive trigeminal neuralgia. J Clin Neurosci 15:516-519

27. Tate R, Rubin LM, Krajewski KC (2011) Treatment of refractory trigeminal neuralgia with intravenous phenytoin. Am J Health Syst Pharm 68:2059-2061

28. Lu DP, Lu WI, Lu GP (2011) Phenytoin (Dilantin) and acupuncture therapy in the treatment of intractable oral and facial pain. Acupunct Electrother Res 36:65-84

29. Jorns TP, Zakrzewska JM (2007) Evidence-based approach to the medical management of trigeminal neuralgia. Br J Neurosurg 21:253-261

30. Canavero S, Bonicalzi V (2006) Drug therapy of trigeminal neuralgia. Expert Rev Neurother 6:429-440

31. Yang M, Zhou M, He L et al (2011) Non-antiepileptic drugs for trigeminal neuralgia. Cochrane Database Syst Rev. doi:10.1002/14651858.CD004029

32. Lenchig S, Cohen J, Patin D (2012) A minimally invasive surgical technique for the treatment of posttraumatic trigeminal neuropathic pain with peripheral nerve stimulation. Pain physician 15:E725-E732

33. Zakrzewska JM, Akram H (2011) Neurosurgical interventions for the treatment of classical trigeminal neuralgia. Cochrane Database Syst Rev. doi:10.1002/14651858.CD007312 
34. Trindade De Almeida AR, Secco LC, Carruthers A (2011) Handling botulinum toxins: an updated literature review. Dermatol Surg 37:1553-1565

35. Humeau Y, Doussau F, Grant NJ et al (2000) How botulinum and tetanus neurotoxins block neurotransmitter release. Biochimie 82:427-446

36. Pearce LB, First ER, MacCallum RD et al (1997) Pharmacologic characterization of botulinum toxin for basic science and medicine. Toxicon 35:1373-1412

37. Frampton JE (2012) OnabotulinumtoxinA (BOTOX(R)): a review of its use in the prophylaxis of headaches in adults with chronic migraine. Drugs 72:825-845

38. Schulte-Mattler WJ, Martinez-Castrillo JC (2006) Botulinum toxin therapy of migraine and tension-type headache: comparing different botulinum toxin preparations. Eur J Neurol 13(Suppl 1):51-54

39. Casale R, Tugnoli V (2008) Botulinum toxin for pain. Drugs R D 9:11-27

40. Porta M, Camerlingo M (2005) Headache and botulinum toxin. J Headache Pain 6:325-327

41. McMahon HT, Foran P, Dolly JO et al (1992) Tetanus toxin and botulinum toxins type $A$ and $B$ inhibit glutamate, gamma-aminobutyric acid, aspartate, and met-enkephalin release from synaptosomes. Clues to the locus of action. J Biol Chem 267:21338-21343

42. Purkiss JR, Welch MJ, Doward S et al (1997) Capsaicin stimulates release of substance $P$ from dorsal root ganglion neurons via two distinct mechanisms. Biochem Soc Trans 25:542S

43. Welch MJ, Purkiss JR, Foster KA (2000) Sensitivity of embryonic rat dorsal root ganglia neurons to Clostridium botulinum neurotoxins. Toxicon 38:245-258

44. Bach-Rojecky L, Lackovic Z (2005) Antinociceptive effect of botulinum toxin type a in rat model of carrageenan and capsaicin induced pain. Croat Med J 46:201-208

45. Cui M, Khanijou S, Rubino J et al (2004) Subcutaneous administration of botulinum toxin A reduces formalin-induced pain. Pain 107:125-133

46. Luvisetto S, Marinelli S, Cobianchi S et al (2007) Anti-allodynic efficacy of botulinum neurotoxin $A$ in a model of neuropathic pain. Neurosci 145:1-4

47. Park HJ, Lee $Y$, Lee J et al (2006) The effects of botulinum toxin A on mechanical and cold allodynia in a rat model of neuropathic pain. Canadian journal of anaesthesia $=$. J canadien d'anesthesie 53:470-477

48. Micheli F, Scorticati MC, Raina G (2002) Beneficial effects of botulinum toxin type a for patients with painful tic convulsif. Clin Neuropharmacol 25:260-262

49. Ngeow WC, Nair R (2010) Injection of botulinum toxin type A (BOTOX) into trigger zone of trigeminal neuralgia as a means to control pain. Oral Surg Oral Med Oral Pathol Oral Radiol Endod 109:e47-e50

50. Allam N, Brasil-Neto JP, Brown G et al (2005) Injections of botulinum toxin type a produce pain alleviation in intractable trigeminal neuralgia. Clin $\mathrm{J}$ Pain 21:182-184

51. Piovesan EJ, Teive HG, Kowacs PA et al (2005) An open study of botulinumA toxin treatment of trigeminal neuralgia. Neurology 65:1306-1308

52. Karsenty $G$, Denys $P$, Amarenco $G$ et al (2008) Botulinum toxin A (Botox) intradetrusor injections in adults with neurogenic detrusor overactivity/ neurogenic overactive bladder: a systematic literature review. Eur Urol 53:275-287

53. Singh JA, Fitzgerald PM (2011) Botulinum toxin for shoulder pain: a cochrane systematic review. J Rheumatol 38:409-418

54. Mangera A, Andersson KE, Apostolidis A et al (2011) Contemporary management of lower urinary tract disease with botulinum toxin $A$ : a systematic review of botox (onabotulinumtoxinA) and dysport (abobotulinumtoxinA). Eur Urol 60:784-795

55. Hansen H, Manchikanti L, Simopoulos TT et al (2012) A systematic evaluation of the therapeutic effectiveness of sacroiliac joint interventions. Pain Physician 15:E247-E278

56. Wu CJ, Lian YJ, Zheng YK et al (2012) Botulinum toxin type A for the treatment of trigeminal neuralgia: results from a randomized, double-blind, placebo-controlled trial. Cephalalgia 32:443-450

57. Bohluli B, Motamedi MH, Bagheri SC et al (2011) Use of botulinum toxin A for drug-refractory trigeminal neuralgia: preliminary report. Oral Surg Oral Med Oral Pathol Oral Radiol Endod 111:47-50

58. Zuniga C, Diaz S, Piedimonte F et al (2008) Beneficial effects of botulinum toxin type A in trigeminal neuralgia. Arq Neuropsiquiatr 66:500-503

59. Turk U, Ilhan S, Alp R et al (2005) Botulinum toxin and intractable trigeminal neuralgia. Clin Neuropharmacol 28:161-162
60. Borodic GE, Acquadro MA (2002) The use of botulinum toxin for the treatment of chronic facial pain. J Pain 3:21-27

61. Gazerani P, Staahl C, Drewes AM et al (2006) The effects of Botulinum Toxin type A on capsaicin-evoked pain, flare, and secondary hyperalgesia in an experimental human model of trigeminal sensitization. Pain 122:315-325

62. Gazerani P, Pedersen NS, Staahl C et al (2009) Subcutaneous Botulinum toxin type $A$ reduces capsaicin-induced trigeminal pain and vasomotor reactions in human skin. Pain 141:60-69

doi:10.1186/1129-2377-14-72

Cite this article as: Hu et al:: Therapeutic efficacy and safety of botulinum toxin type $\mathrm{A}$ in trigeminal neuralgia: a systematic review. The Journal of Headache and Pain 2013 14:72.

\section{Submit your manuscript to a SpringerOpen ${ }^{\odot}$ journal and benefit from:}

- Convenient online submission

- Rigorous peer review

- Immediate publication on acceptance

- Open access: articles freely available online

- High visibility within the field

- Retaining the copyright to your article

Submit your next manuscript at $>$ springeropen.com 